\title{
EANM position paper on the role of radiobiology in nuclear medicine
}

\author{
An Aerts ${ }^{1} \cdot$ Uta Eberlein $^{2}$ (D) Sören Holm ${ }^{3} \cdot$ Roland Hustinx $^{4} \cdot$ Mark Konijnenberg $^{5} \cdot$ Lidia Strigari $^{6}$. \\ Fijs W.B. van Leeuwen ${ }^{7} \cdot$ Gerhard Glatting $^{8} \cdot$ Michael Lassmann $^{2}$
}

Received: 24 March 2021 / Accepted: 28 March 2021 / Published online: 29 April 2021

(C) The Author(s) 2021

\section{Executive Summary}

With an increasing variety of radiopharmaceuticals for diagnostic or therapeutic nuclear medicine as valuable diagnostic or treatment option, radiobiology plays an important role in supporting optimizations. This comprises particularly safety and efficacy of radionuclide therapies, specifically tailored to each patient. As absorbed dose rates and absorbed dose distributions in space and time are very different between external irradiation and systemic radionuclide exposure, distinct radiation-induced biological responses are expected in nuclear medicine, which need to be explored. This calls for a dedicated nuclear medicine radiobiology. Radiobiology findings and absorbed dose measurements will enable an improved estimation and prediction of efficacy and adverse effects. Moreover, a better understanding on the fundamental biological mechanisms underlying tumor and normal tissue responses will help to identify predictive and prognostic biomarkers as well as biomarkers for treatment follow-up. In addition, radiobiology can form the basis for the development of radiosensitizing strategies and radioprotectant agents. Thus, EANM believes that, beyond in vitro and preclinical evaluations, radiobiology will bring important added value to clinical studies and to clinical teams. Therefore, EANM strongly supports active collaboration between radiochemists, radiopharmacists, radiobiologists, medical physicists, and physicians to foster research toward precision nuclear medicine.

Keywords Radiobiology $\cdot$ Dosimetry $\cdot$ Biodosimetry $\cdot$ Biomarkers $\cdot$ Radionuclide therapy

\section{Introduction}

In recent years, the number of radiopharmaceuticals for diagnostic and therapeutic applications has increased considerably. In addition, theranostics are being developed that use the same molecular targeting platform for both imaging and treatment. This has led to an increased medical use in both

G.G. and M.L. shared senior authorship.

This article is part of the Topical Collection on Radiation biology

Uta Eberlein

Eberlein_U@ukw.de

1 Radiobiology Unit, Institute for Environment, Health and Safety, Belgian Nuclear Research Centre (SCK CEN), Mol, Belgium

2 Department of Nuclear Medicine, University Hospital Würzburg, Würzburg, Germany

3 Department of Clinical Physiology, Nuclear Medicine and PET, Rigshospitalet, University Hospital Copenhagen,

Copenhagen, Denmark malignant as well as benign conditions. Consequently, an improved understanding of the biological processes, with special regard to the effects of ionizing radiation to normal tissues and tumors, is required. This is to determine the absorbed doseeffect relationship more precisely, as a prerequisite for achieving an optimal diagnostic or therapeutic outcome. In general, absorbed doses are low $(<20 \mathrm{mGy})$ for most organs in

4 Division of Nuclear Medicine and Oncological Imaging, University Hospital of Liège, GIGA-CRC in vivo Imaging, University of Liège, Liège, Belgium

5 Department of Radiology and Nuclear Medicine, Erasmus MC, Rotterdam, The Netherlands

6 Medical Physics Department, IRCCS Azienda Ospedaliero-Universitaria di Bologna, Bologna, Italy

7 Interventional Molecular Imaging Laboratory, Department of Radiology, Leiden University Medical Center,

Leiden, The Netherlands

8 Medical Radiation Physics, Department of Nuclear Medicine, Ulm University, Ulm, Germany 
diagnostic procedures [1]. However, when multiple diagnostic examinations or therapeutic applications are undertaken, this is no longer the case. Repeated diagnostic irradiations can result in cumulative absorbed doses in normal organs and tissues up to a few hundred milligray [2]. For therapies, absorbed doses can exceed previously suggested absorbed dose limits (e.g., 23 Gy for the kidneys in peptide receptor radionuclide therapies [3]). For absorbed doses of $<1$ Gy, stochastic effects of ionizing radiation may be observed, whereas for therapies, a mixture of stochastic and deterministic effects is expected. Radiation-related adverse effects strongly depend on both the individual absorbed doses [4] and the individual radiation sensitivity [5-8]. Thus, without an individualized approach in radionuclide therapy, a group of patients may be over-treated, jeopardizing patient safety. Conversely, patients may be undertreated, leading to suboptimal treatment efficacy.

Systemic radiation delivery via radiopharmaceuticals is inherently different from irradiation by external radiation sources. As a consequence, distinct radiation-induced biological responses are expected for radiopharmaceuticals posing considerable challenges for in vitro, preclinical and clinical studies investigating radionuclide applications. Several research topics are suggested that should be addressed with regard to radiobiology in relation to the systemic use of radiopharmaceuticals and which have not yet been rigorously investigated [9-11]. Presently, there are limited studies related to the use of radiobiology in nuclear medicine. Typical examples of such studies are provided in Table 1.

In addition, in a recent review it was stated that, for radiation oncology, incomplete physics and dosimetry reporting limits the progress of radiobiology [74]. The authors concluded that there is not only a crucial deficiency on experimental details but also a lack of interaction between medical physicists and radiobiologists. The reporting of results pertaining to radiobiology in nuclear medicine is often provided in activities rather than absorbed doses (Table 1). Therefore, future radiobiology studies in nuclear medicine will benefit from including good practice of dosimetry reporting [75]. Conversely, dosimetry calculations should be based on available experimental biological data.

Consequently, in nuclear medicine, patient care optimization principles, which include not only absorbed dose or dose rate parameters but also radiobiological parameters, should be integrated. To this end, close interaction and collaboration between radiochemists, radiopharmacists, radiobiologists, medical physicists, and physicians will be needed.

\section{Radiobiology}

Radiobiology (also known as radiation biology) is a branch of biology concerned with the biological effects of ionizing radiation on living organisms. Radiobiology studies the interactions of ionizing radiation on atomic and molecular structures and consequently their induced effects on cells, tissues, and organs, both normal and diseased. As such, radiobiology enhances the understanding of biological outcome (harm or benefit) from ionizing radiation exposure.

When ionizing radiation impinges living matter, it deposits energy along its path leading to atomic ionization, thereby damaging biological molecular structures (Fig. 1). In the common paradigm, DNA is considered the critical target for radiation damage [76]. However, not only DNA, but also proteins, lipids and metabolites may be modified by ionizing radiation $[77,78]$. In direct action, absorption of ionizing radiation will happen at the site of the atoms of the cellular molecules. Subsequent ionization events may cause breakage of chemical bonds. It may also convert atoms and molecules into free radicals with very reactive unpaired electrons that can further react with neighboring molecules after which a chain of damaging reactions may occur. The indirect effect from the absorption of ionizing radiation is the production of free hydroxyl and other highly reactive radicals, due to the hydrolysis of water molecules. Despite their short existence, they can still diffuse to and damage other cellular molecules. Moreover, oxygen can create reactive oxygen or nitrogen radical species with greater stability, longer lifetimes, and thus wider diffusion possibilities [76, 78]. The abundance of these oxygen radicals generates a condition known as oxidative stress which can further impact cellular signaling and alter metabolic pathways resulting in, among others, cell death mechanisms, senescence, and inflammation [78, 79]. Furthermore, ionizing radiation can harm supramolecular structures like cellular membranes, mitochondria, the endoplasmic reticulum, the Golgi apparatus, the lysosomal system, and the cytoskeleton [80]. Finally, also aspects beyond cellular boundaries are increasingly being considered in radiobiology, like the tumor microenvironment, intercellular communication, immune responses, and the abscopal effect [81, 82].

Research in radiobiology can rely on the newest techniques and insights in biology in general and is exploiting (epi)genomics, proteomics, metabolomics, high-throughput screening, and exploring new models like stem cells, organoids, in vivo orthotopic and subcutaneous patient-derived xenograft models, or siRNA- or CRISPR/Cas9-derived models. These are anticipated to lead to new hypotheses to understand the effects generated from ionizing radiation on biological systems and to improve therapies based on ionizing radiation $[78,83]$.

Today, improved insights into the dose-response effects caused by ionizing radiation on tumor cell killing as well as on acute and long-term normal tissue collateral damage are impacting greatly treatment planning in external beam radiation therapy (EBRT) $[83,84]$. Of several models, the linearquadratic (LQ) model has been best validated by experimental and clinical data to describe cell survival fractions. The 


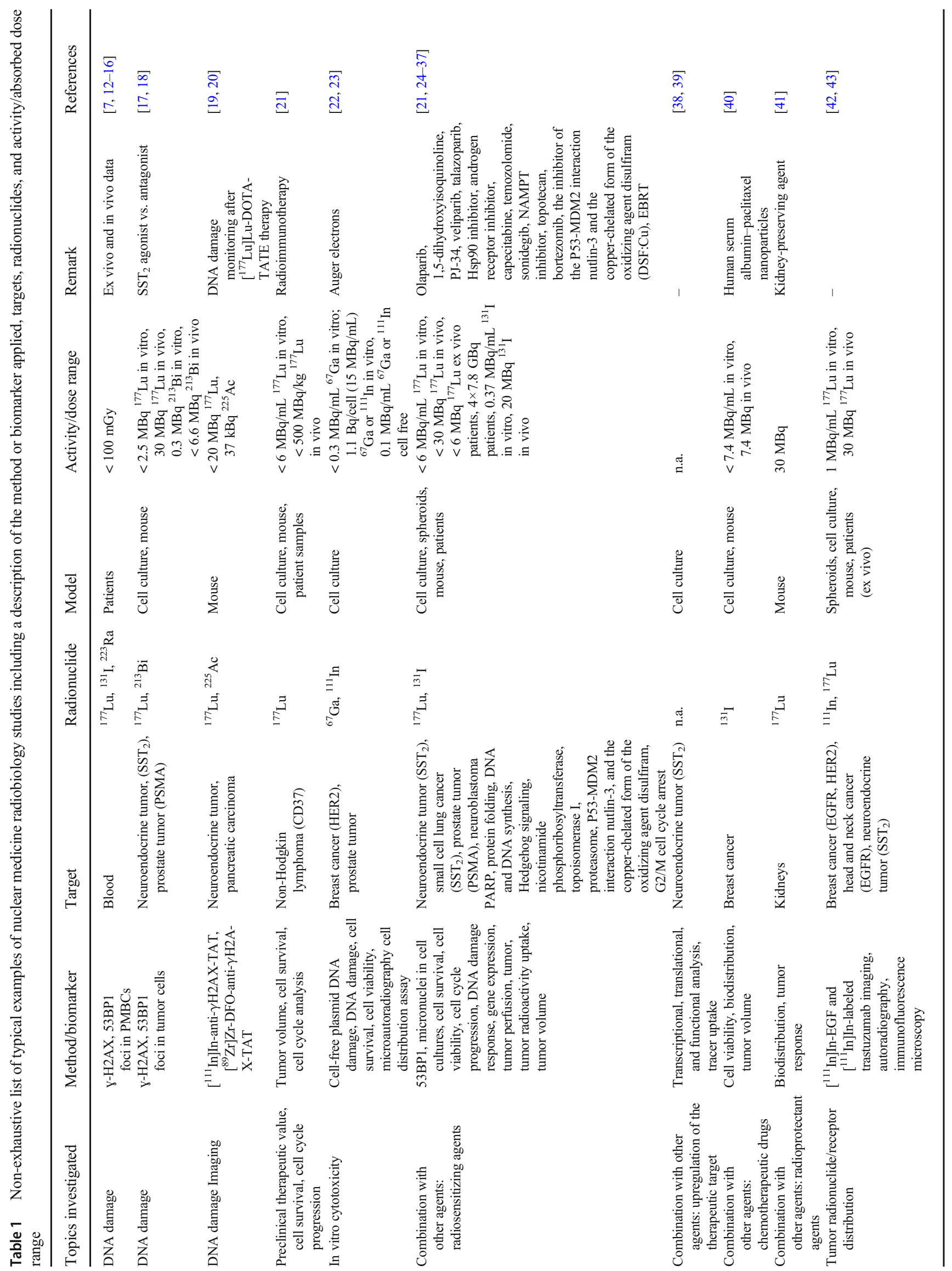




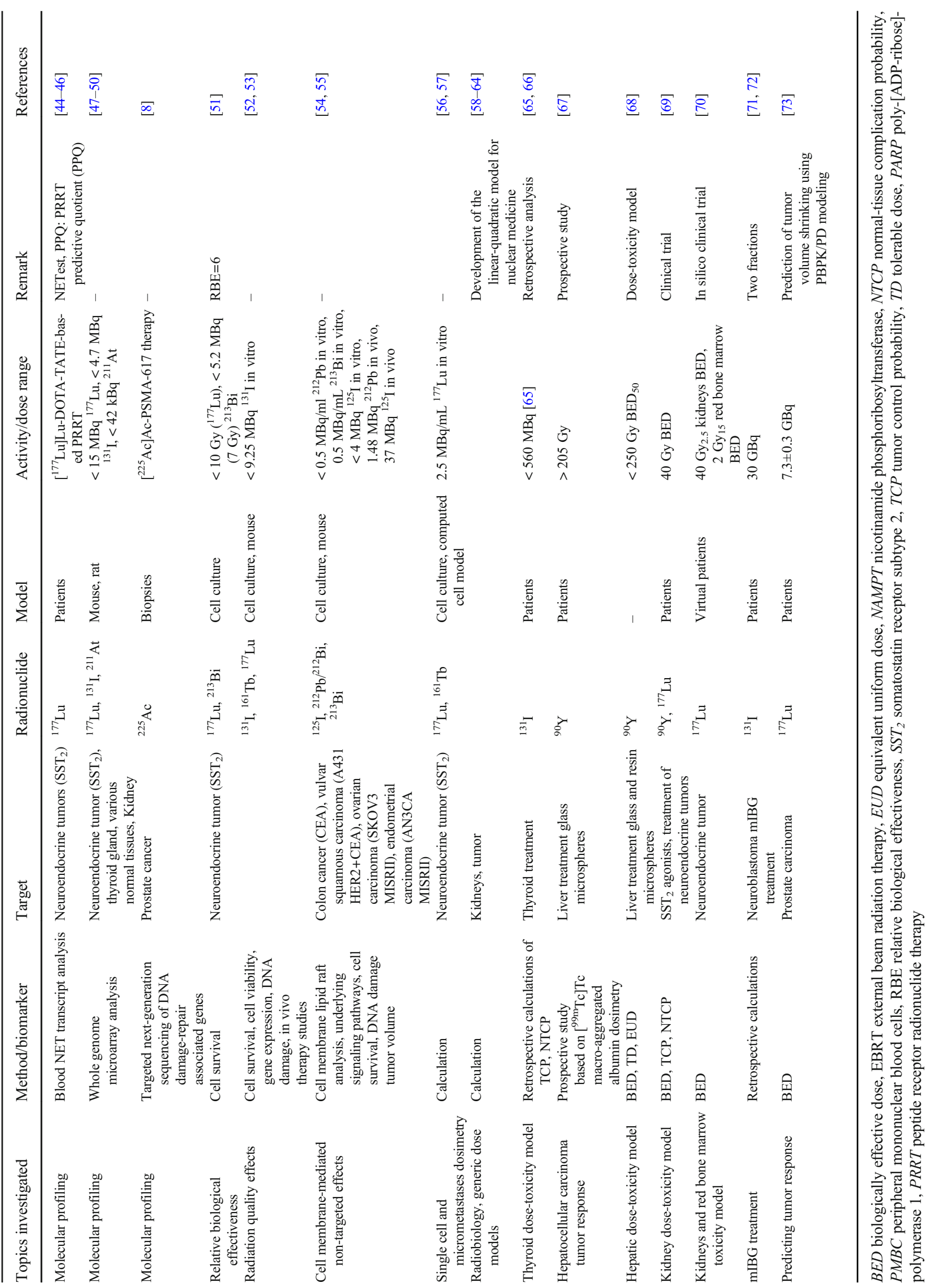




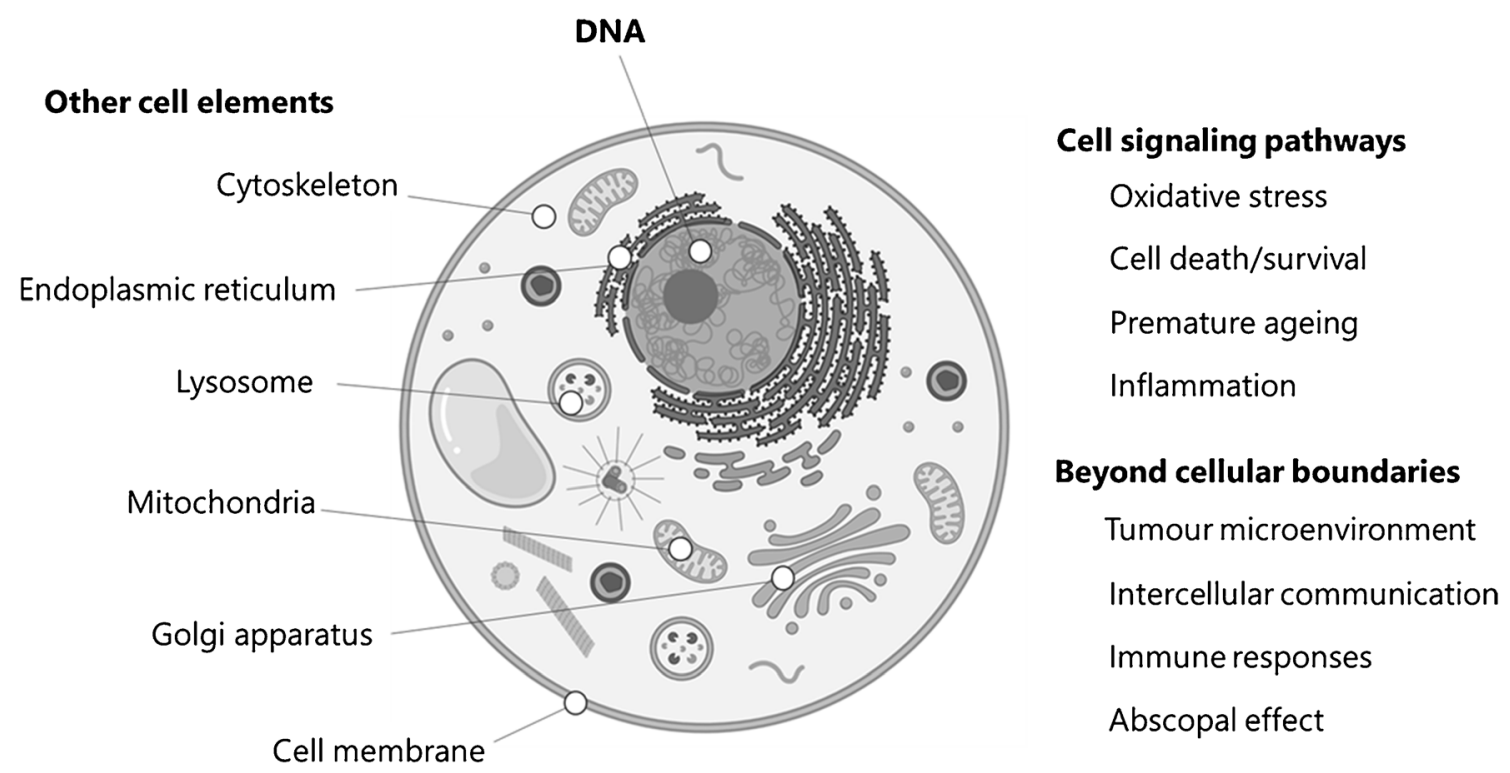

Fig. 1 Interaction of ionizing radiation with cellular matter, DNA, and much more. DNA and other cell elements as potential targets for ionizing radiation damage. Ionizing radiation also impacts cell signaling pathways like oxidative stress, cell death and survival pathways, premature aging, and inflammation, all of which moreover are highly interconnected. Also, aspects beyond the cellular boundaries must be considered, like intercellular communication, the tumor microenvironment, the immune system, and the abscopal effect. Image created using BioRender.com selection of accurate LQ parameters, $\alpha, \beta$, and $\alpha / \beta$, is pivotal for a reliable estimate of radiation response. Clinically, the LQ model is mainly used to estimate equivalent radiotherapy schedules (e.g., calculate the equivalent dose in 2-Gy fractions), but increasingly also to predict tumor control probability (TCP) and normal tissue complication probability (NTCP) using logistic models [76, 85]. In addition, radiobiological discoveries are guiding clinical trials that test EBRT combined with inhibitors of the DNA damage response and immune or cell cycle checkpoint inhibitors. To have maximum impact for individual patients, predictive biomarkers should be identified that enable the rational selection of treatments to combine with EBRT. Further research into the radiobiology of tumor metabolism, cancer stem cells, and the tumor microenvironment has the potential to translate current knowledge and future gains to the clinic [83].

The question arises whether there is a need for a dedicated nuclear medicine radiobiology or whether we can rely on radiobiological models derived for EBRT or brachytherapy.

The response of a living system to an irradiation strongly depends on the distribution of absorbed doses across space and time. As these dose distributions in EBRT and brachytherapy are very different to those in radionuclide therapy, extrapolation of EBRT or brachytherapy radiobiology to radionuclide therapy is not straightforward. Indeed, the specific physical characteristics of radionuclide therapy (mixed radiation qualities, time-varying and protracted exposure, low absorbed dose rates, and inhomogeneous dose distributions) differ from those of conventional EBRT (short exposure time, high absorbed dose rate, and mostly homogeneous irradiation fields) and brachytherapy (even in the low dose rate case there is a well-defined source distribution). As a result, the responses of irradiated tissues and of the human/patient are expected to be different for radionuclide therapy [10, 86, 87]. For example, due to the time-varying and comparatively low dose rates in radionuclide therapies, the DNA damage induction and repair may strongly differ compared to EBRT [7, 12, $13,75]$. Consequently, there is a need for the generation and application of more radiobiological knowledge specific for nuclear medicine diagnostic and therapeutic procedures.

Efforts to gather more evidence in radiobiology regarding systemic exposure to ionizing radiation in nuclear medicine applications have been increasing recently; this is illustrated in this paragraph at the example of $\left[{ }^{177} \mathrm{Lu}\right] \mathrm{Lu}$ DOTA-[Tyr3] octreotate $\left(\left[{ }^{177} \mathrm{Lu}\right] \mathrm{Lu}\right.$-DOTA-TATE) radionuclide therapy in patients with advanced, progressive, somatostatin receptor subtype $\left(\mathrm{SST}_{2}\right)$-positive midgut neuroendocrine tumors (NETs) that was studied in the NETTER-1 phase III trial [88]. Even though $\left[{ }^{177} \mathrm{Lu}\right] \mathrm{Lu}$-DOTA-TATE is clearly successful in terms of survival benefits, current figures could be further improved. In addition, treatment is limited by potential adverse effects on the kidneys and the bone marrow, hindering the use to its full potential. This emphasizes the need to further optimize $\left[{ }^{177} \mathrm{Lu}\right] \mathrm{Lu}$-DOTA-TATE radionuclide therapy to further improve efficacy while reducing toxicity. This includes improved dosimetry hand in hand with a deep biological evaluation of superior radionuclides, improved $\mathrm{SST}_{2}$ ligands, increased $\mathrm{SST}_{2}$ levels, the role of tumor microenvironment, and combinations with immunotherapy, targeted therapy or DNA modulating agents, as well as predictive markers for improved patient selection and treatment follow-up [24, 44, 45, 89-91]. 


\section{Position of the EANM}

Radiobiology is particularly relevant for nuclear medicine therapies, as these treatments differ substantially from irradiation by external radiation sources. This is highlighted in the common strategic research agenda for radiation protection in medicine [92] developed by the five medical societies involved in the medical application of ionizing radiation, which later founded the European Alliance for Medical Radiation Protection Research (EURAMED) (https://www.euramed.eu/) ${ }^{1}$. An improved understanding of the biological processes with special regard to the effects of ionizing radiation to normal tissues and tumors is needed to individualize the use of existing and future developed radiopharmaceuticals. Therefore, the radiobiological knowledge concerning the specific needs of nuclear medicine (e.g., patient-specific and tumor-specific radiation sensitivity, dose-effect relationships, spatio-temporal properties, therapy response, normal tissue effects, role of microenvironment and systemic reactions, combination therapies) must be obtained and considered together with physical and medical parameters in the development of nuclear medicine procedures. This will also foster the principles stated in the EC Directive 2013/59/Euratom, article 56, that exposures of target volumes in nuclear medicine treatments shall be individually planned and their delivery appropriately verified [93]. How to interpret the $\mathrm{EC}$ directive for nuclear medicine therapies is further detailed in the recently published EANM position paper on article 56 of the Council Directive 2013/59/Euratom [94].

Absorbed dose measurements can be combined with radiobiological parameters to enable an improved estimation and prediction of efficacy and adverse effects, which can further support treatment planning [94]. This additional input is presently, however, very rarely used, as only limited studies related to therapeutic use of radiopharmaceuticals and including radiobiological parameters are available. Of note, the precision dosimetry approach to describe the dose on the cellular and subcellular level in targeted radionuclide therapy is under development [56, 57].

In diagnostic nuclear medicine applications, especially in longitudinal procedures, the role of radiobiology and the longterm consequences of radiobiology-related findings, such as reported in studies on DNA damage and repair, still has to be defined [95-101]. Currently, these studies provide no evidence that diagnostic nuclear medicine procedures are not safe.

Consequently, EANM believes that, to further optimize nuclear medicine procedures for each individual patient, efforts should be undertaken to promote the integration of radiobiology within nuclear medicine by endorsing further

\footnotetext{
${ }^{1}$ EURAMED represents the European Association of Nuclear Medicine (EANM), the European Federation of Organizations for Medical Physics (EFOMP), the European Federation of Radiographer Societies (EFRS), the European Society of Radiology (ESR), and the European Society for Radiotherapy and Oncology (ESTRO).
}

research and teaching activities. The knowledge of different disciplines, such as biology, chemistry, medicine, pharmacy, and physics, can then be combined for providing reproducible results, which are, ideally, traceable to metrological standards.

\section{Essential radiobiological studies}

The nature of radiation exposure resulting from nuclear medicine procedures is diverse and comprises different radiation qualities, absorbed doses, dose rates, and temporal and spatial dose distributions $[102,103]$. Low doses are encountered in diagnostic procedures as well as from out-of-target therapeutic exposures. High doses are expected within the tumor and in the close proximity of the tumor during radionuclide therapy. The determination of the absorbed dose to the tissue and on a (sub-)cellular scale are a prerequisite for defining dose-effect relationships, both in estimating (pre-)clinical therapy outcome and normal tissue toxicity as well as in assessing the cellular and molecular mechanisms, including repair capacity (Fig. 2).

With the ambition to maximize the benefits of radiopharmaceutical products that are effective and safe for each individual patient, preclinical and translational science undertakes dedicated research to understand the biological characteristics of tumor and normal tissue intrinsic radiosensitivities and the fundamental biological mechanisms underlying the therapeutic and short- and long-term cytotoxic effects of radiopharmaceutical products, as well as determining the dose-effect relationship herein (Fig. 2) [9-11]. Essential aspects to investigate related to patient- and tumor-specific radiosensitivities include genetic background and underlying anomalies that impact radiosensitivity, target distribution, tumor heterogeneity, tumor micro-environment, and tumor growth and metastatic spread. Important endpoints to be assessed in tumor and healthy tissue responses are DNA damage, damage to other cell elements, death and survival pathways, oxidative stress and inflammation, effect on the immune and systemic reactions, and repair capacities. To this end, high-end molecular and cellular biology tools, omics data analyses (proteomic, transcriptomic, genomic, radiomics) as well as bioimaging (microscopy, PET/ CT or SPECT/CT, autoradiography) are available. As such, radiobiological data may reveal patient-specific radiation sensitivity traits useful as predictive biomarkers of response for a personalized radionuclide therapy regimen (e.g., genomic traits, target level and distribution, anomalies in signaling pathways altering radiosensitivity) as well as biomarkers useful for therapy response monitoring, both on a therapeutic aspect as well as for normal tissue damage. Radiobiological findings may also be used as input for the development of radiosensitizers or radioprotectant agents. Moreover, the radiobiology of fractionation schemes (how many/how much activity per fraction) as well as the radiobiology of combination therapies (combinations of radionuclide therapy with 


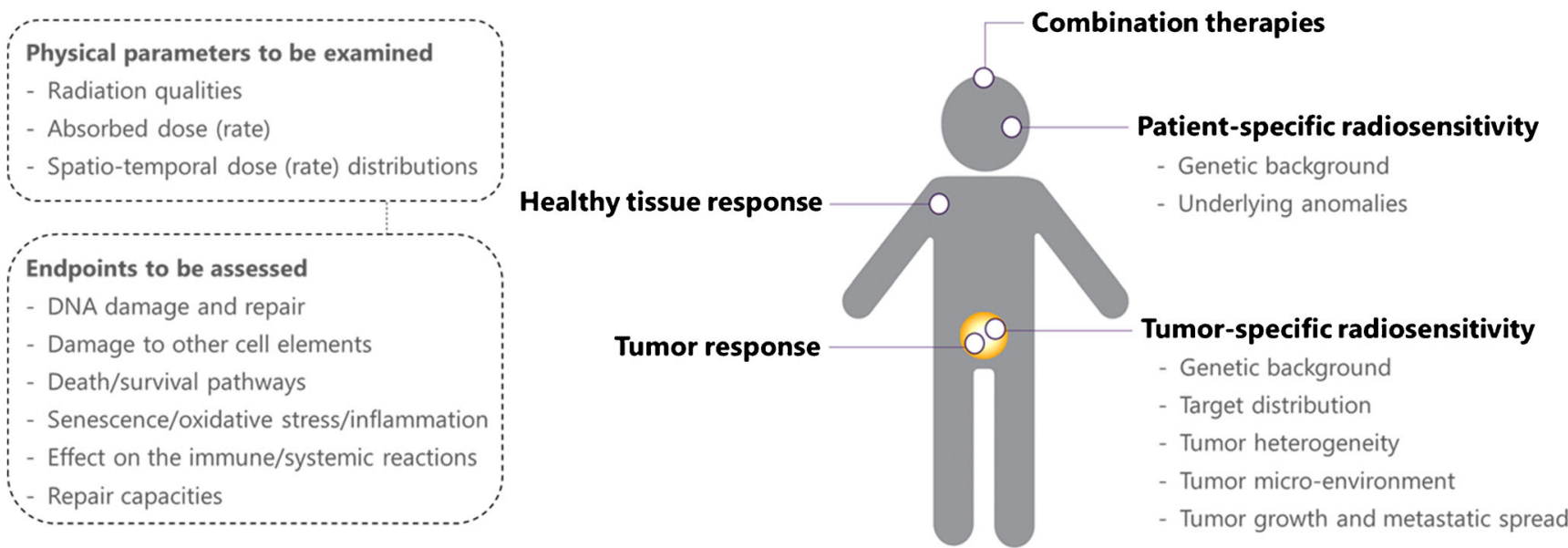

Fig. 2 Contributions of radiobiology to nuclear medicine. Radiobiology helps to understand patient- and tumor-specific radiosensitivities. In addition, radiobiology is fundamental to a mechanistic understanding of the therapeutic capacity of nuclear medicine agents and their potential short- and long-term toxicities, including the dose-effect relationships herein. Biological data will serve as input for dosimetry, together leading to a more accurate estimation of efficacy and adverse effects.

chemotherapy, tyrosine kinase inhibitors, immunotherapy, hormone therapy, or radiosensitizers) $[9,25]$ is not well explored and could be helpful in defining optimal treatment strategies. Finally, standardization of biological study protocols as well as depositing study data in repositories is required to allow comparison and combining of cohorts.

Some publications, regarding both external and internal irradiation, indicate that there is a very low dose range $(<$ 10 mGy) which shows a different dose response compared to higher doses [99, 104-107]. Therefore, extrapolating from higher absorbed doses and dose rates to very low doses and dose rates is not straightforward and needs further research. It is likely that other, different, biological responses exist after low-dose and high-dose ionizing radiation exposure using radiopharmaceuticals for both tumor and normal tissues.

\section{Investigating low-dose radiation effects in nuclear medicine}

The linear-no-threshold (LNT) model based on the extrapolation of epidemiological data at high absorbed doses is currently used to estimate the risk at low doses [108], although this is a matter of debate $[109,110]$. An important aspect of the justification of using this model is that radiation carcinogenesis has been assumed to be primarily driven by the damage to the DNA and subsequent mutation of growth-regulating genes in target cells. Yet, a number of other potential mechanisms contributing to and modulating radiation carcinogenesis have been proposed, including epigenetic mechanisms of gene regulation such as DNA methylation and miRNA expression, transmissible genomic instability, bystander effects, and adaptive response. The extent to which these modulating effects
Ideally, this will lead to patient-specific dosing schemes. Moreover, further fundamental knowledge about the biological mechanisms underlying tumor and healthy tissue responses will help in identifying predictive and prognostic biomarkers as well as biomarkers for treatment follow-up. In addition, it can form the basis for the development of combination therapies, including radiosensitizing and radioprotectant strategies. Image created using BioRender.com

and non-mutational mechanisms challenge the validity of the LNT risk extrapolation model needs to be determined. For this purpose, the use of well-validated animal and human cellular/ tissue models of radiation carcinogenesis (both solid cancers and leukemias) is required. In addition, also non-cancer effects (e.g., cardiovascular and neurocognitive) should be considered and studied [111].

The key question here is whether the LNT model is valid for internal radiation exposure such as that encountered from nuclear medicine procedures with typically low dose rates, heterogeneous dose distributions, and a protracted nature of exposure. Therefore, the determination of corresponding lowdose-effect relationships can be a basis for risk assessment also in radiation protection (ALARA, LNT hypothesis, second cancer risk), e.g., in medical imaging or staff exposure.

To describe and monitor such effects, studies are needed to identify biomarkers for assessing short-term or medium-/longterm stochastic radiation risks (cancer and non-cancer) that (1) are sufficiently sensitive in the low-dose range $(<100 \mathrm{mGy})$, (2) are strongly linked to medium-/long-term side effects of ionizing radiation, and (3) possess definite dose/dose rate/dose fractionation/radiation quality dependencies.

\section{Investigating therapeutic radiation effects in nuclear medicine}

Currently, dose-effect relations are not fully utilized in most radionuclide therapies, as these therapies are given at a minimal activity that is deemed safe in all patients and effective to some extent. This often results in suboptimal therapy delivery. Radioembolization therapies arguably form the exception to this rule, as both normal liver thresholds and tumor target 
absorbed doses are considered as input to the treatment planning of these therapies.

More studies should be undertaken to determine TCP and NTCP curves for specific radionuclide therapies. In this context, radiobiological data (e.g., LQ $\alpha / \beta$ parameters and repair kinetics) can serve as input for better dose-effect modeling [58, $59,65,70]$ taking into account the radiation quality, dose rate, dose fractionation, and dose distribution on the tissue as well as on the (sub)cellular scale [60]. Finally, results from comparison studies with external beam radiation therapy could inform on better treatment strategies in nuclear medicine.

Radiobiology and dosimetry should be integrated in all stages of the development of individualized radionuclide therapy drugs. Preclinical experiments should deliver the radiobiological data through standardized and controlled settings with multiple cancer models to study response variability. Radiobiological concepts should ideally form the basis for the design of clinical trial protocols. Phase I studies focus on safety and thus should consider both absorbed dose and individual patient radiosensitivity. Phase II studies should ideally be based on absorbed dose thresholds and individual radiosensitivity. In many cases, the choice is made for a phase II trial with fixed activity at the maximum tolerable activity from phase I in order to simplify the clinical protocol. However, without absorbed doses available, it is impossible to build knowledge on doseeffect relationships and prospective clinical trials based on individually absorbed doses are crucial [67].

\section{Discussion}

Radiobiological knowledge is not yet used in many nuclear medicine applications, or it is used only in a basic phenomenological manner, such as that integrated in the model of biologically effective dose (BED). This can be attributed to two main reasons:

1. Detailed radiobiological knowledge is currently not readily available, because of

a. The specifics of nuclear medicine procedures and their multiple parameters involved (dose, dose rate, individual DNA repair capacity, ...) as well as the heterogeneity of the conditions being treated.

b. The complexity of its integration into the clinical procedures for example due to technical constraints (e.g., microscopes, bone marrow biopsies) or missing know-how.

c. The associated patient load (time per patient per measurement).

d. The resources and costs associated (personnel, supplies, and others).
2. The phenomenological parameters (LQ $\alpha / \beta$ parameters, DNA repair) known from EBRT are incorrectly thought to suffice fully for the needs of all nuclear medicine applications.

All of the above points need to be addressed for continued improvement of nuclear medicine procedures, including the adequate integration of radiobiology. To solve item 1.a requires intensified research as previously discussed, while item $1 . b$ needs education and training of all involved, scientists and physicians. Both call for the need of standardized procedures to produce reliable data. Lastly, items 1.c and 1.d are an issue for cost-benefit analysis which is mandatory for all medical procedures. This applies also to item 2 whose applicability and justification should be applied adhering to the requirements of best available science and cost-benefit analysis.

Thus, to develop an optimal nuclear medicine procedure one needs to acquire and include all knowledge and appropriate commitment from all involved in the process. This will inevitably include time investment from the patient for more measurements. Such collection of data and inclusion of a priori knowledge is the required input for a rigorous costbenefit analysis. Implemented therapies will then be well founded, both scientifically and in terms of cost and effort.

\section{Conclusion}

While the role of radiobiology for diagnostics remains to be clarified, there is a clear role for radiobiology in optimizing the benefits of therapeutic radiopharmaceuticals to ensure that they are effective and safe for each individual patient. Just as radiobiology data are routinely used in EBRT treatment planning, nuclear medicine could also benefit from a deeper integration of such data. Therefore, there is a need to better define the dose-effect relationships of systemic ionizing radiation for tumors as well as for normal tissue. As absorbed dose rates and absorbed dose distributions in space and time are very different between external irradiation and systemic radionuclide exposure, distinct radiation-induced biological responses are expected in nuclear medicine and need to be explored. It is expected that a better understanding of radiobiological parameters can contribute to fully exploit the capabilities of new and existing nuclear medicine applications to be effective and safe for each individual patient. To this end, a strong link between radiochemists, radiopharmacists, radiobiologists, medical physicists, and physicians is warranted to design sound study designs. In particular, the inclusion of radiobiologists in the clinical team will be advantageous. 
Acknowledgments We thank all EANM committee members, who responded to the nuclear medicine radiobiology questionnaire by the EANM Radiobiology Working Group, for their valuable input.

Funding Open Access funding enabled and organized by Projekt DEAL.

\section{Declarations}

Conflict of interest M.L. has received research grants by IPSEN Pharma and Nordic Nanovector. A.A., G.G., M.K., S.H., R.H, and F.v.L. have no conflicts of interest to declare that are relevant to the content of this article. U.E., L.S. and R.H. have no conflicts of interest to declare. M.L. and R.H. are members of the EANM board. The other authors are members of the following EANM committees: Radiation Protection (G.G., S.H.); Dosimetry (U.E., M.K., L.S.); Translational Molecular Imaging \& Therapy (A.A., F.v.L.).

Ethical approval This article does not contain any studies with human participants or animals performed by any of the authors.

Open Access This article is licensed under a Creative Commons Attribution 4.0 International License, which permits use, sharing, adaptation, distribution and reproduction in any medium or format, as long as you give appropriate credit to the original author(s) and the source, provide a link to the Creative Commons licence, and indicate if changes were made. The images or other third party material in this article are included in the article's Creative Commons licence, unless indicated otherwise in a credit line to the material. If material is not included in the article's Creative Commons licence and your intended use is not permitted by statutory regulation or exceeds the permitted use, you will need to obtain permission directly from the copyright holder. To view a copy of this licence, visit http://creativecommons.org/licenses/by/4.0/.

\section{References}

1. Eberlein U, Bröer JH, Vandevoorde C, Santos P, Bardiès M, Bacher K, et al. Biokinetics and dosimetry of commonly used radiopharmaceuticals in diagnostic nuclear medicine - a review. Eur J Nucl Med Mol Imaging. 2011;38:2269-81. https://doi.org/ 10.1007/s00259-011-1904-z.

2. Chawla SC, Federman N, Zhang D, Nagata K, Nuthakki S, McNitt-Gray M, et al. Estimated cumulative radiation dose from PET/CT in children with malignancies: a 5-year retrospective review. Pediatr Radiol. 2010;40:681-6. https://doi.org/10.1007/ s00247-009-1434-Z.

3. Bodei L, Mueller-Brand J, Baum RP, Pavel ME, Hörsch D, O'Dorisio MS, et al. The joint IAEA, EANM, and SNMMI practical guidance on peptide receptor radionuclide therapy (PRRNT) in neuroendocrine tumours. Eur J Nucl Med Mol Imaging. 2013;40:800-16. https://doi.org/10.1007/s00259-012-2330-6.

4. Strigari L, Konijnenberg M, Chiesa C, Bardies M, Du Y, Gleisner $\mathrm{KS}$, et al. The evidence base for the use of internal dosimetry in the clinical practice of molecular radiotherapy. Eur J Nucl Med Mol Imaging. 2014:41:1976-88. https://doi.org/10.1007/s00259-0142824-5.

5. Jia X, Guo K, Gao R, Yu Y, Yang A. Radiosensitivity-related postirradiation hypothyroidism in Graves' disease patients. Hormones (Athens). 2019;18:267-72. https://doi.org/10.1007/ s42000-019-00123-7.

6. De-Colle C, Yaromina A, Hennenlotter J, Thames H, Mueller AC, Neumann T, et al. Ex vivo $\gamma \mathrm{H} 2 \mathrm{AX}$ radiation sensitivity assay in prostate cancer: inter-patient and intra-patient heterogeneity. Radiother Oncol. 2017;124:386-94. https://doi.org/10.1016/j. radonc.2017.08.020.

7. Eberlein U, Nowak C, Bluemel C, Buck AK, Werner RA, Scherthan $\mathrm{H}$, et al. DNA damage in blood lymphocytes in patients after ${ }^{177} \mathrm{Lu}$ peptide receptor radionuclide therapy. Eur J Nucl Med Mol Imaging. 2015;42:1739-49. https://doi.org/10.1007/s00259015-3083-9.

8. Kratochwil C, Giesel FL, Heussel CP, Kazdal D, Endris V, Nientiedt $C$, et al. Patients resistant against PSMA-targeting $\alpha$ radiation therapy often harbor mutations in DNA damage-repairassociated genes. J Nucl Med. 2020;61:683-8. https://doi.org/10. 2967/jnumed.119.234559.

9. Terry SYA, Nonnekens J, Aerts A, Baatout S, de Jong M, Cornelissen B, et al. Call to arms: need for radiobiology in molecular radionuclide therapy. Eur J Nucl Med Mol Imaging. 2019;46:1588-90. https://doi.org/10.1007/s00259-019-04334-3.

10. Morris ZS, Wang AZ, Knox SJ. The radiobiology of radiopharmaceuticals. Semin Radiat Oncol. 2021;31:20-7. https://doi.org/ 10.1016/j.semradonc.2020.07.002.

11. Verburg FA, Nonnekens J, Konijnenberg MW, de Jong M. To go where no one has gone before: the necessity of radiobiology studies for exploration beyond the limits of the "holy Gray" in radionuclide therapy. Eur J Nucl Med Mol Imaging. 2021. https://doi. org/10.1007/s00259-020-05147-5.

12. Eberlein U, Scherthan H, Bluemel C, Peper M, Lapa C, Buck AK, et al. DNA damage in peripheral blood lymphocytes of thyroid cancer patients after radioiodine therapy. J Nucl Med. 2016;57: 173-9. https://doi.org/10.2967/jnumed.115.164814.

13. Schumann S, Eberlein U, Muhtadi R, Lassmann M, Scherthan H. DNA damage in leukocytes after internal ex-vivo irradiation of blood with the alpha-emitter Ra-223. Sci Rep. 2018;8:2286. https://doi.org/10.1038/s41598-018-20364-7.

14. Schumann S, Scherthan H, Lapa C, Serfling S, Muhtadi R, Lassmann M, et al. DNA damage in blood leucocytes of prostate cancer patients during therapy with $\left({ }^{177}\right)$ Lu-PSMA. Eur J Nucl Med Mol Imaging. 2019;46:1723-32. https://doi.org/10.1007/ s00259-019-04317-4.

15. Denoyer D, Lobachevsky P, Jackson P, Thompson M, Martin OA, Hicks RJ. Analysis of ${ }^{177} \mathrm{Lu}$-DOTA-octreotate therapy-induced DNA damage in peripheral blood lymphocytes of patients with neuroendocrine tumors. J Nucl Med. 2015;56:505-11. https://doi. org/10.2967/jnumed.114.145581.

16. Schumann S, Eberlein U, Lapa C, Müller J, Serfling S, Lassmann $\mathrm{M}$, et al. $\alpha$-Particle-induced DNA damage tracks in peripheral blood mononuclear cells of $\left[{ }^{223} \mathrm{Ra}^{2} \mathrm{RaCl}_{2}\right.$-treated prostate cancer patients. Eur J Nucl Med Mol Imaging. 2021. https://doi.org/10. 1007/s00259-020-05170-6.

17. Dalm SU, Nonnekens J, Doeswijk GN, de Blois E, van Gent DC, Konijnenberg MW, et al. Comparison of the therapeutic response to treatment with a ${ }^{177} \mathrm{Lu}$-labeled somatostatin receptor agonist and antagonist in preclinical models. J Nucl Med. 2016;57:260 5. https://doi.org/10.2967/jnumed.115.167007.

18. Nonnekens J, Chatalic KL, Molkenboer-Kuenen JD, Beerens CE, Bruchertseifer F, Morgenstern A, et al. ${ }^{213} \mathrm{Bi}$-labeled prostatespecific membrane antigen-targeting agents induce DNA doublestrand breaks in prostate cancer xenografts. Cancer Biother Radiopharm. 2017;32:67-73. https://doi.org/10.1089/cbr.2016. 2155.

19. O'Neill E, Kersemans V, Allen PD, Terry SYA, Torres JB, Mosley M, et al. Imaging DNA damage repair in vivo after ${ }^{177}$ Lu-DOTATATE therapy. J Nucl Med. 2020;61:743-50. https://doi.org/10.2967/jnumed.119.232934.

20. Poty S, Mandleywala K, O'Neill E, Knight JC, Cornelissen B, Lewis JS. ${ }^{89}$ Zr-PET imaging of DNA double-strand breaks for the early monitoring of response following $\alpha$ - and $\beta$-particle 
radioimmunotherapy in a mouse model of pancreatic ductal adenocarcinoma. Theranostics. 2020;10:5802-14. https://doi.org/10. 7150/thno. 44772.

21. Pichard A, Marcatili S, Karam J, Constanzo J, Ladjohounlou R, Courteau A, et al. The therapeutic effectiveness of ${ }^{177} \mathrm{Lu}$-lilotomab in B-cell non-Hodgkin lymphoma involves modulation of G2/M cell cycle arrest. Leukemia. 2020;34:1315-28. https://doi.org/10. 1038/s41375-019-0677-4.

22. Othman MFB, Verger E, Costa I, Tanapirakgul M, Cooper MS, Imberti $\mathrm{C}$, et al. In vitro cytotoxicity of Auger electron-emitting $\left[{ }^{67} \mathrm{Ga}\right]$ Ga-trastuzumab. Nucl Med Biol. 2020;80-81:57-64. https://doi.org/10.1016/j.nucmedbio.2019.12.004

23. Othman MF, Mitry NR, Lewington VJ, Blower PJ, Terry SY. Reassessing gallium-67 as a therapeutic radionuclide. Nucl Med Biol. 2017;46:12-8. https://doi.org/10.1016/j.nucmedbio.2016. 10.008 .

24. Hofving T, Sandblom V, Arvidsson Y, Shubbar E, Altiparmak G, Swanpalmer J, et al. ${ }^{177} \mathrm{Lu}$-octreotate therapy for neuroendocrine tumours is enhanced by Hsp90 inhibition. Endocr Relat Cancer. 2019;26:437-49. https://doi.org/10.1530/erc-18-0509.

25. Chan T, O'Neill E, Habjan C, Cornelissen B. Combination strategies to improve targeted radionuclide therapy. J Nucl Med. 2020. https://doi.org/10.2967/jnumed.120.248062.

26. Nonnekens J, van Kranenburg M, Beerens CE, Suker M, Doukas $\mathrm{M}$, van Eijck $\mathrm{CH}$, et al. Potentiation of peptide receptor radionuclide therapy by the PARP inhibitor olaparib. Theranostics. 2016;6:1821-32. https://doi.org/10.7150/thno.15311.

27. Purohit NK, Shah RG, Adant S, Hoepfner M, Shah GM, Beauregard JM. Potentiation of ${ }^{177} \mathrm{Lu}$-octreotate peptide receptor radionuclide therapy of human neuroendocrine tumor cells by PARP inhibitor. Oncotarget. 2018;9:24693-706. https://doi.org/ 10.18632/oncotarget.25266.

28. Cullinane C, Waldeck K, Kirby L, Rogers BE, Eu P, Tothill RW, et al. Enhancing the anti-tumour activity of ${ }^{177}$ Lu-DOTAoctreotate radionuclide therapy in somatostatin receptor-2 expressing tumour models by targeting PARP. Sci Rep. 2020;10:10196. https://doi.org/10.1038/s41598-020-67199-9.

29. Lundsten S, Spiegelberg D, Stenerlöw B, Nestor M. The HSP90 inhibitor onalespib potentiates ${ }^{177} \mathrm{LuDOTATATE}$ therapy in neuroendocrine tumor cells. Int J Oncol. 2019;55:1287-95. https:// doi.org/10.3892/ijo.2019.4888.

30. Claringbold PG, Price RA, Turner JH. Phase I-II study of radiopeptide ${ }^{177} \mathrm{Lu}$-octreotate in combination with capecitabine and temozolomide in advanced low-grade neuroendocrine tumors. Cancer Biother Radiopharm. 2012;27:561-9. https://doi. org/10.1089/cbr.2012.1276.

31. Claringbold PG, Brayshaw PA, Price RA, Turner JH. Phase II study of radiopeptide ${ }^{177} \mathrm{Lu}$-octreotate and capecitabine therapy of progressive disseminated neuroendocrine tumours. Eur J Nucl Med Mol Imaging. 2011;38:302-11. https://doi.org/10.1007/ s00259-010-1631-x.

32. Bison SM, Haeck JC, Bol K, Koelewijn SJ, Groen HC, Melis M, et al. Optimization of combined temozolomide and peptide receptor radionuclide therapy (PRRT) in mice after multimodality molecular imaging studies. EJNMMI Res. 2015;5:62. https://oi.org/ 10.1186/s13550-015-0142-y.

33. Spetz J, Langen B, Rudqvist N, Parris TZ, Helou K, Nilsson O, et al. Hedgehog inhibitor sonidegib potentiates ${ }^{177} \mathrm{Lu}$-octreotate therapy of GOT1 human small intestine neuroendocrine tumors in nude mice. BMC Cancer. 2017;17:528. https://doi.org/10.1186/ s12885-017-3524-x.

34. Elf AK, Bernhardt P, Hofving T, Arvidsson Y, Forssell-Aronsson E, Wängberg B, et al. NAMPT inhibitor GMX1778 enhances the efficacy of ${ }^{177}$ Lu-DOTATATE treatment of neuroendocrine tumors. J Nucl Med. 2017;58:288-92. https://doi.org/10.2967/ jnumed.116.177584.
35. Lewin J, Cullinane C, Akhurst T, Waldeck K, Watkins DN, Rao A, et al. Peptide receptor chemoradionuclide therapy in small cell carcinoma: from bench to bedside. Eur J Nucl Med Mol Imaging. 2015;42:25-32. https://doi.org/10.1007/s00259-014-2888-2.

36. Tesson M, Rae C, Nixon C, Babich JW, Mairs RJ. Preliminary evaluation of prostate-targeted radiotherapy using ${ }^{131}$ I-MIP-1095 in combination with radiosensitising chemotherapeutic drugs. J Pharm Pharmacol. 2016;68:912-21. https://doi.org/10.1111/ jphp.12558.

37. Corroyer-Dulmont A, Falzone N, Kersemans V, Thompson J, Allen DP, Able S, et al. Improved outcome of ${ }^{131} \mathrm{I}$-mIBG treatment through combination with external beam radiotherapy in the SK-N-SH mouse model of neuroblastoma. Radiother Oncol. 2017;124:488-95. https://doi.org/10.1016/j.radonc.2017.05.002.

38. Taelman VF, Radojewski P, Marincek N, Ben-Shlomo A, Grotzky A, Olariu CI, et al. Upregulation of key molecules for targeted imaging and therapy. J Nucl Med. 2016;57:1805-10. https://doi.org/10.2967/jnumed.115.165092.

39. Veenstra MJ, van Koetsveld PM, Dogan F, Farrell WE, Feelders RA, Lamberts SWJ, et al. Epidrug-induced upregulation of functional somatostatin type 2 receptors in human pancreatic neuroendocrine tumor cells. Oncotarget. 2018;9:14791-802. https:/doi. org/10.18632/oncotarget.9462.

40. Tian L, Chen Q, Yi X, Wang G, Chen J, Ning P, et al. Radionuclide I-131 labeled albumin-paclitaxel nanoparticles for synergistic combined chemo-radioisotope therapy of cancer. Theranostics. 2017;7:614-23. https://doi.org/10.7150/thno. 17381.

41. Andersson CK, Shubbar E, Schüler E, Åkerström B, Gram M, Forssell-Aronsson EB. Recombinant $\alpha(1)$-microglobulin is a potential kidney protector in ${ }^{177} \mathrm{Lu}$-octreotate treatment of neuroendocrine tumors. J Nucl Med. 2019;60:1600-4. https://doi.org/10. 2967/jnumed.118.225243.

42. Falzone N, Lee BQ, Able S, Malcolm J, Terry S, Alayed Y, et al. Targeting micrometastases: the effect of heterogeneous radionuclide distribution on tumor control probability. J Nucl Med. 2018;60:250-8. https://doi.org/10.2967/jnumed.117.207308.

43. Feijtel D, Doeswijk GN, Verkaik NS, Haeck JC, Chicco D, Angotti C, et al. Inter and intra-tumor somatostatin receptor 2 heterogeneity influences peptide receptor radionuclide therapy response. Theranostics. 2021;11.

44. Bodei L, Kidd MS, Singh A, van der Zwan WA, Severi S, Drozdov IA, et al. PRRT genomic signature in blood for prediction of ${ }^{177} \mathrm{Lu}$-octreotate efficacy. Eur J Nucl Med Mol Imaging. 2018;45:1155-69. https://doi.org/10.1007/s00259-018-3967-6.

45. Bodei L, Kidd MS, Singh A, van der Zwan WA, Severi S, Drozdov IA, et al. PRRT neuroendocrine tumor response monitored using circulating transcript analysis: the NETest. Eur J Nucl Med Mol Imaging. 2020;47:895-906. https://doi.org/10.1007/ s00259-019-04601-3.

46. Ćwikła JB, Bodei L, Kolasinska-Ćwikła A, Sankowski A, Modlin IM, Kidd M. Circulating transcript analysis (NETest) in GEPNETs treated with somatostatin analogs defines therapy. J Clin Endocrinol Metab. 2015;100:E1437-45. https://doi.org/10.1210/ jc.2015-2792.

47. Spetz J, Rudqvist N, Langen B, Parris TZ, Dalmo J, Schüler E, et al. Time-dependent transcriptional response of GOT1 human small intestine neuroendocrine tumor after ${ }^{177} \mathrm{Lu}[\mathrm{Lu}]$-octreotate therapy. Nucl Med Biol. 2018;60:11-8. https://doi.org/10.1016/j. nucmedbio.2018.01.006.

48. Rudqvist N, Spetz J, Schüler E, Parris TZ, Langen B, Helou K, et al. Transcriptional response to ${ }^{131} \mathrm{I}$ exposure of rat thyroid gland. PLoS One. 2017;12:e0171797. https://doi.org/10.1371/journal. pone. 0171797 .

49. Langen B, Rudqvist N, Helou K, Forssell-Aronsson E. Microarray studies on ${ }^{211}$ At administration in BALB/c nude mice indicate 
systemic effects on transcriptional regulation in nonthyroid tissues. J Nucl Med. 2017;58:346-53. https://doi.org/10.2967/ jnumed.116.176958.

50. Schüler E, Rudqvist N, Parris TZ, Langen B, Helou K, ForssellAronsson E. Transcriptional response of kidney tissue after ${ }^{177} \mathrm{Lu}-$ octreotate administration in mice. Nucl Med Biol. 2014;41:23847. https://doi.org/10.1016/j.nucmedbio.2013.12.001.

51. Chan HS, de Blois E, Morgenstern A, Bruchertseifer F, de Jong $\mathrm{M}$, Breeman $\mathrm{W}$, et al. In vitro comparison of ${ }^{213} \mathrm{Bi}$ - and ${ }^{177} \mathrm{Lu}-$ radiation for peptide receptor radionuclide therapy. PLoS One. 2017;12:e0181473. https://doi.org/10.1371/journal.pone. 0181473.

52. Kumar C, Jayakumar S, Pandey BN, Samuel G, Venkatesh M. Cellular and molecular effects of beta radiation from I-131 on human tumor cells: a comparison with gamma radiation. Curr Radiopharm. 2014;7:138-43. https://doi.org/10.2174/ 1874471007666140716115938.

53. Müller C, Umbricht CA, Gracheva N, Tschan VJ, Pellegrini G, Bernhardt $\mathrm{P}$, et al. Terbium-161 for PSMA-targeted radionuclide therapy of prostate cancer. Eur J Nucl Med Mol Imaging. 2019;46: 1919-30. https://doi.org/10.1007/s00259-019-04345-0.

54. Paillas S, Ladjohounlou R, Lozza C, Pichard A, Boudousq V, Jarlier M, et al. Localized irradiation of Cell Membrane by Auger Electrons Is Cytotoxic Through Oxidative StressMediated Nontargeted Effects. Antioxid Redox Signal. 2016;25: 467-84. https://doi.org/10.1089/ars.2015.6309.

55. Ladjohounlou R, Lozza C, Pichard A, Constanzo J, Karam J, Le Fur P, et al. Drugs that modify cholesterol metabolism Alter the p38/JNK-mediated targeted and nontargeted response to alpha and auger radioimmunotherapy. Clin Cancer Res. 2019;25:4775-90. https://doi.org/10.1158/1078-0432.Ccr-18-3295.

56. Tamborino G, De Saint-Hubert M, Struelens L, Seoane DC, Ruigrok EAM, Aerts A, et al. Cellular dosimetry of $\left[{ }^{177} \mathrm{Lu}\right] \mathrm{Lu}-$ DOTA-[Tyr $\left.{ }^{3}\right]$ octreotate radionuclide therapy: the impact of modeling assumptions on the correlation with in vitro cytotoxicity. EJNMMI Phys. 2020;7:8. https://doi.org/10.1186/s40658020-0276-5.

57. Alcocer-Ávila ME, Ferreira A, Quinto MA, Morgat C, Hindié E, Champion C. Radiation doses from ${ }^{161} \mathrm{~Tb}$ and ${ }^{177} \mathrm{Lu}$ in single tumour cells and micrometastases. EJNMMI Phys. 2020;7:33. https://doi.org/10.1186/s40658-020-00301-2.

58. Strigari L, Benassi M, Chiesa C, Cremonesi M, Bodei L, D'Andrea M. Dosimetry in nuclear medicine therapy: radiobiology application and results. Q J Nucl Med Mol Imaging. 2011;55: 205-21.

59. Sarnelli A, Guerriero F, Botta F, Ferrari M, Strigari L, Bodei L, et al. Therapeutic schemes in ${ }^{177} \mathrm{Lu}$ and ${ }^{90}$ Y-PRRT: radiobiological considerations. Q J Nucl Med Mol Imaging. 2017;61:216-31. https://doi.org/10.23736/s1824-4785.16.02744-8.

60. Hobbs RF, Howell RW, Song H, Baechler S, Sgouros G. Redefining relative biological effectiveness in the context of the EQDX formalism: implications for alpha-particle emitter therapy. Radiat Res. 2014;181:90-8. https://doi.org/10.1667/rr13483.1.

61. Dale R, Carabe-Fernandez A. The radiobiology of conventional radiotherapy and its application to radionuclide therapy. Cancer Biother Radiopharm. 2005;20:47-51. https://doi.org/10.1089/cbr. 2005.20.47.

62. Wessels BW, Konijnenberg MW, Dale RG, Breitz HB, Cremonesi M, Meredith RF, et al. MIRD pamphlet no. 20: the effect of model assumptions on kidney dosimetry and responseimplications for radionuclide therapy. J Nucl Med. 2008;49: 1884-99. https://doi.org/10.2967/jnumed.108.053173.

63. Gustafsson J, Nilsson P, Gleisner KS. On the biologically effective dose (BED)-using convolution for calculating the effects of repair: I. Analytical considerations. Phys Med Biol. 2013;58: 1507-27. https://doi.org/10.1088/0031-9155/58/5/1507.
64. Gustafsson J, Nilsson P, Gleisner KS. On the biologically effective dose (BED)-using convolution for calculating the effects of repair: II. Numerical considerations. Phys Med Biol. 2013;58: 1529-48. https://doi.org/10.1088/0031-9155/58/5/1529.

65. Strigari L, Sciuto R, Benassi M, Bergomi S, Nocentini S, Maini CL. A NTCP approach for estimating the outcome in radioiodine treatment of hyperthyroidism. Med Phys. 2008;35:3903-10. https://doi.org/10.1118/1.2964089.

66. Walrand S, Hesse M, Jamar F. Statistical and radiobiological analysis of the so-called thyroid stunning. EJNMMI Res. 2015;5:67. https://doi.org/10.1186/s13550-015-0144-9.

67. Garin E, Tselikas L, Guiu B, Chalaye J, Edeline J, de Baere T, et al. Personalised versus standard dosimetry approach of selective internal radiation therapy in patients with locally advanced hepatocellular carcinoma (DOSISPHERE-01): a randomised, multicentre, open-label phase 2 trial. Lancet Gastroenterol Hepatol. 2020. https://doi.org/10.1016/s2468-1253(20)30290-9.

68. Walrand S, Hesse M, Jamar F, Lhommel R. A hepatic dosetoxicity model opening the way toward individualized radioembolization planning. J Nucl Med. 2014;55:1317-22. https://doi.org/10.2967/jnumed.113.135301.

69. Sundlöv A, Sjogreen-Gleisner K, Svensson J, Ljungberg M, Olsson T, Bernhardt P, et al. Individualised ${ }^{177}$ Lu-DOTATATE treatment of neuroendocrine tumours based on kidney dosimetry. Eur J Nucl Med Mol Imaging. 2017;44:1480-9. https://doi.org/ 10.1007/s00259-017-3678-4.

70. Jiménez-Franco LD, Kletting P, Beer AJ, Glatting G. Treatment planning algorithm for peptide receptor radionuclide therapy considering multiple tumor lesions and organs at risk. Med Phys. 2018;45:3516-23. https://doi.org/10.1002/mp.13049.

71. Mínguez P, Gustafsson J, Flux G, Gleisner KS. Biologically effective dose in fractionated molecular radiotherapy - application to treatment of neuroblastoma with ${ }^{131} \mathrm{I}$-mIBG. Phys Med Biol. 2016;61:2532-51. https://doi.org/10.1088/0031-9155/61/6/2532.

72. Flux GD, Chittenden SJ, Saran F, Gaze MN. Clinical applications of dosimetry for mIBG therapy. Q J Nucl Med Mol Imaging. 2011;55:116-25.

73. Kletting P, Thieme A, Eberhardt N, Rinscheid A, D'Alessandria $\mathrm{C}$, Allmann J, et al. Modeling and predicting tumor response in radioligand therapy. J Nucl Med. 2019;60:65-70. https://doi.org/ 10.2967/jnumed.118.210377.

74. Draeger E, Sawant A, Johnstone C, Koger B, Becker S, Vujaskovic Z, et al. A dose of reality: how 20 years of incomplete physics and dosimetry reporting in radiobiology studies may have contributed to the reproducibility crisis. Int J Radiat Oncol Biol Phys. 2020;106:243-52. https://doi.org/10.1016/j.ijrobp.2019.06. 2545.

75. Lassmann M, Chiesa C, Flux G, Bardiès M. EANM Dosimetry Committee guidance document: good practice of clinical dosimetry reporting. Eur J Nucl Med Mol Imaging. 2011;38:192-200. https://doi.org/10.1007/s00259-010-1549-3.

76. Castellucci P, Deandreis D, Krizsán A, Mirzaei S, Prior J, Sattler $\mathrm{B}$, et al. European nuclear medicine guide. A joint publication by EANM and UEMS/EBNM 2020.

77. Bolus NE. Basic review of radiation biology and terminology. J Nucl Med Technol. 2017;45:259-64. https://doi.org/10.2967/ jnmt.117.195230.

78. Reisz JA, Bansal N, Qian J, Zhao W, Furdui CM. Effects of ionizing radiation on biological molecules - mechanisms of damage and emerging methods of detection. Antioxid Redox Signal. 2014;21:260-92. https://doi.org/10.1089/ars.2013.5489.

79. Baselet B, Sonveaux P, Baatout S, Aerts A. Pathological effects of ionizing radiation: endothelial activation and dysfunction. Cell Mol Life Sci. 2019;76:699-728. https://doi.org/10.1007/s00018018-2956-z. 
80. Somosy Z. Radiation response of cell organelles. Micron. 2000;31:165-81. https://doi.org/10.1016/s0968-4328(99)000839.

81. McKelvey KJ, Hudson AL, Back M, Eade T, Diakos CI. Radiation, inflammation and the immune response in cancer. Mamm Genome. 2018;29:843-65. https://doi.org/10.1007/ s00335-018-9777-0.

82. Ramadan R, Baatout S, Aerts A, Leybaert L. The role of connexin proteins and their channels in radiation-induced atherosclerosis. Cell Mol Life Sci. 2021. https://doi.org/10.1007/s00018-02003716-3.

83. Kirsch DG, Diehn M, Kesarwala AH, Maity A, Morgan MA, Schwarz JK, et al. The future of radiobiology. J Natl Cancer Inst. 2018;110:329-40. https://doi.org/10.1093/jnci/djx231.

84. Shirato H, Le QT, Kobashi K, Prayongrat A, Takao S, Shimizu S, et al. Selection of external beam radiotherapy approaches for precise and accurate cancer treatment. J Radiat Res. 2018;59:i2-i10. https://doi.org/10.1093/jrr/rrx092.

85. van Leeuwen CM, Oei AL, Crezee J, Bel A, Franken NAP, Stalpers LJA, et al. The alfa and beta of tumours: a review of parameters of the linear-quadratic model, derived from clinical radiotherapy studies. Radiat Oncol. 2018;13:96. https://doi.org/ 10.1186/s13014-018-1040-z.

86. Pouget JP, Lozza C, Deshayes E, Boudousq V, Navarro-Teulon I. Introduction to radiobiology of targeted radionuclide therapy. Front Med (Lausanne). 2015;2:12. https://doi.org/10.3389/fmed. 2015.00012.

87. Sgouros G, Bodei L, McDevitt MR, Nedrow JR. Radiopharmaceutical therapy in cancer: clinical advances and challenges. Nat Rev Drug Discov. 2020;19:589-608. https:// doi.org/10.1038/s41573-020-0073-9.

88. Strosberg J, El-Haddad G, Wolin E, Hendifar A, Yao J, Chasen B, et al. Phase 3 trial of ${ }^{177} \mathrm{Lu}$-Dotatate for midgut neuroendocrine tumors. N Engl J Med. 2017;376:125-35. https://doi.org/10.1056/ NEJMoa1607427.

89. Brabander T, Nonnekens J, Hofland J. The next generation of peptide receptor radionuclide therapy. Endocr Relat Cancer. 2019;26:C7-c11. https://doi.org/10.1530/erc-19-0186.

90. Feijtel D, de Jong M, Nonnekens J. Peptide receptor radionuclide therapy: looking back, looking forward. Curr Top Med Chem. 2020. https://doi.org/10.2174/1568026620666200226104652.

91. Bodei L, Schöder H, Baum RP, Herrmann K, Strosberg J, Caplin $\mathrm{M}$, et al. Molecular profiling of neuroendocrine tumours to predict response and toxicity to peptide receptor radionuclide therapy. Lancet Oncol. 2020;21:e431-e43. https://doi.org/10.1016/s14702045(20)30323-5.

92. European Association of Nuclear Medicine (EANM), European Federation of Organizations for Medical Physics (EFOMP), European Federation of Radiographer Societies (ESR), European Society of Radiology (ESR), European Society for Radiotherapy and Oncology (ESTRO). Common strategic research agenda for radiation protection in medicine. Insights Imaging. 2017;8:18397. https://doi.org/10.1007/s13244-016-0538-x.

93. Council of the European Union. European Council Directive 2013/59/Euratom on basic safety standards for protection against the dangers arising from exposure to ionising radiation and repealing directives 89/618/Euratom, 90/641/Euratom, 96/29/ Euratom, 97/43/Euratom and 2003/122/Euratom. Off J EU. 2014;L13:1-73.

94. Konijnenberg M, Herrmann K, Kobe C, Verburg F, Hindorf C, Hustinx R, et al. EANM position paper on article 56 of the Council Directive 2013/59/Euratom (basic safety standards) for nuclear medicine therapy. Eur J Nucl Med Mol Imaging. 2020. https:// doi.org/10.1007/s00259-020-05038-9.

95. May MS, Brand M, Wuest W, Anders K, Kuwert T, Prante O, et al. Induction and repair of DNA double-strand breaks in blood lymphocytes of patients undergoing ${ }^{18} \mathrm{~F}-\mathrm{FDG}$ PET/CT examinations. Eur J Nucl Med Mol Imaging. 2012;39:1712-9. https://doi. org/10.1007/s00259-012-2201-1.

96. Schnarr K, Carter TF, Gillis D, Webber C, Lemon JA, Dayes I, et al. Biological response of positron emission tomography scan exposure and adaptive response in humans. Dose Response. 2015;13:1559325815611904. https://doi.org/10.1177/ 1559325815611904.

97. Nautiyal A, Mondal T, Mukherjee A, Mitra D, Kaushik A, Goel $\mathrm{HC}$, et al. Quantification of DNA damage in patients undergoing non-contrast and contrast enhanced whole body PET/CT investigations using comet assay and micronucleus assay. Int J Radiat Biol. 2019;95:710-9. https://doi.org/10.1080/09553002.2019. 1577569.

98. Schmeiser HH, Muehlbauer KR, Mier W, Baranski AC, Neels O, Dimitrakopoulou-Strauss A, et al. DNA damage in human whole blood caused by radiopharmaceuticals evaluated by the comet assay. Mutagenesis. 2019;34:239-44. https://doi.org/10.1093/ mutage/gez007.

99. Schumann S, Scherthan H, Frank T, Lapa C, Muller J, Seifert S, et al. DNA damage in blood leukocytes of prostate cancer patients undergoing PET/CT examinations with $\left[{ }^{68} \mathrm{Ga}\right] \mathrm{Ga}$-PSMA I\&T. Cancers (Basel). 2020;12:388. https://doi.org/10.3390/ cancers12020388.

100. Brix G, Günther E, Rössler U, Endesfelder D, Kamp A, Beer A, et al. Double-strand breaks in lymphocyte DNA of humans exposed to $\left[{ }^{18} \mathrm{~F}\right]$ fluorodeoxyglucose and the static magnetic field in PET/MRI. EJNMMI Res. 2020;10:43. https://doi.org/10.1186/ s13550-020-00625-1.

101. Rief M, Hartmann L, Geisel D, Richter F, Brenner W, Dewey M. DNA double-strand breaks in blood lymphocytes induced by twoday ${ }^{99 \mathrm{~m}} \mathrm{Tc}-\mathrm{MIBI}$ myocardial perfusion scintigraphy. Eur Radiol. 2018;28:3075-81. https://doi.org/10.1007/s00330-017-5239-4.

102. European Association of Nuclear Medicine, Flux G, Stokke C, (Editors). Internal Dosimetry Task Force Report. Treatment planning for molecular radiotherapy: potential and prospects. 2017.

103. Stokke C, Gabiña PM, Solný P, Cicone F, Sandström M, Gleisner $\mathrm{KS}$, et al. Dosimetry-based treatment planning for molecular radiotherapy: a summary of the 2017 report from the Internal Dosimetry Task Force. EJNMMI Phys. 2017;4:27. https://doi. org/10.1186/s40658-017-0194-3.

104. Beels L, Bacher K, De Wolf D, Werbrouck J, Thierens H. Gamma-H2AX foci as a biomarker for patient X-ray exposure in pediatric cardiac catheterization: are we underestimating radiation risks? Circulation. 2009;120:1903-9. https://doi.org/10.1161/ circulationaha.109.880385.

105. Beels L, Werbrouck J, Thierens H. Dose response and repair kinetics of gamma-H2AX foci induced by in vitro irradiation of whole blood and T-lymphocytes with $\mathrm{X}$ - and gamma-radiation. Int J Radiat Biol. 2010;86:760-8. https://doi.org/10.3109/ 09553002.2010.484479.

106. Beels L, Bacher K, Smeets P, Verstraete K, Vral A, Thierens H. Dose-length product of scanners correlates with DNA damage in patients undergoing contrast CT. Eur J Radiol. 2012;81:1495-9. https://doi.org/10.1016/j.ejrad.2011.04.063.

107. Vandevoorde C, Franck C, Bacher K, Breysem L, Smet MH, Ernst $\mathrm{C}$, et al. $\gamma-\mathrm{H} 2 \mathrm{AX}$ foci as in vivo effect biomarker in children emphasize the importance to minimize $\mathrm{x}$-ray doses in paediatric 
CT imaging. Eur Radiol. 2015;25:800-11. https://doi.org/10. 1007/s00330-014-3463-8.

108. ICRP. Publication 103: The 2007 recommendations of the International Commission of Radiological Protection. Ann ICRP. 2007;37(2-4).

109. Doss M. Are we approaching the end of the linear no-threshold era? J Nucl Med. 2018;59:1786-93. https://doi.org/10.2967/ jnumed.118.217182.
110. Pennington CW, Siegel JA. The linear no-threshold model of lowdose radiogenic cancer: a failed fiction. Dose Response. 2019;17: 1559325818824200. https://doi.org/10.1177/1559325818824200.

111. Bouffler S, Auvinen A, Cardis E, Durante M, Jourdain JR, HarmsRingdahl M, et al. Strategic Research Agenda of the Multidisciplinary European Low Dose Initiative (MELODI). 2019

Publisher's note Springer Nature remains neutral with regard to jurisdictional claims in published maps and institutional affiliations. 